\title{
Disease-related microglia heterogeneity in the hippocampus of Alzheimer's disease, dementia with Lewy bodies, and hippocampal sclerosis of aging
}

Adam D. Bachstetter ${ }^{1 *}$, Linda J. Van Eldik ${ }^{1,2}$, Frederick A. Schmitt1,3, Janna H. Neltner ${ }^{1,4}$, Eseosa T. Ighodaro ${ }^{1,2}$, Scott J. Webster ${ }^{1}$, Ela Patel ${ }^{1}$, Erin L. Abner ${ }^{1,5}$, Richard J, Kryscio ${ }^{6,7}$ and Peter T. Nelson ${ }^{1,4}$

\begin{abstract}
Introduction: Neuropathological, genetic, and biochemical studies have provided support for the hypothesis that microglia participate in Alzheimer's disease (AD) pathogenesis. Despite the extensive characterization of AD microglia, there are still many unanswered questions, and little is known about microglial morphology in other common forms of age-related dementia: particularly, dementia with Lewy bodies (DLB) and hippocampal sclerosis of aging (HS-Aging). In addition, no prior studies have attempted to compare and contrast the microglia morphology in the hippocampus of various neurodegenerative conditions.

Results: Here we studied cases with pathologically-confirmed AD $(n=7)$, HS-Aging $(n=7)$, AD + HS-aging $(n=4)$, DLB $(n=12)$, and normal (cognitively intact) controls (NC) $(n=9)$ from the University of Kentucky Alzheimer's Disease Center autopsy cohort. We defined five microglia morphological phenotypes in the autopsy samples: ramified, hypertrophic, dystrophic, rod-shaped, and amoeboid. The Aperio ScanScope digital neuropathological tool was used along with two well-known microglial markers: IBA1 (a marker for both resting and activated microglia) and CD68 (a lysosomal marker in macrophages/microglia associated with phagocytic cells). Hippocampal staining analyses included studies of subregions within the hippocampal formation and nearby white matter. Using these tools and methods, we describe variation in microglial characteristics that show some degree of disease specificity, including, (1) increased microglia density and number in HS-aging and AD + HS-aging; (2) low microglia density in DLB; (3) increased number of dystrophic microglia in HS-aging; and (4) increased proportion of dystrophic to all microglia in DLB.

Conclusions: We conclude that variations in morphologies among microglial cells, and cells of macrophage lineage, can help guide future work connecting neuroinflammatory mechanisms with specific neurodegenerative disease subtypes.
\end{abstract}

Keywords: Aging, Microglia activation, Mixed dementia, Neurodegeneration, Neuroinflammation, Neuropathology

\footnotetext{
* Correspondence: adam.bachstetter@uky.edu

${ }^{1}$ Sanders-Brown Center on Aging, University of Kentucky, 800 S. Limestone

St, Lexington, KY, USA

Full list of author information is available at the end of the article
} 


\section{Introduction}

There is an increasing awareness that microglia may have a pathogenic role in neurodegenerative diseases. The discovery of genetic mutations in CD33 and TREM2 associated with the risk of developing Alzheimer's disease (AD) [1-4] has heightened the interest in defining microglia physiology and pathology in the context of disease. Pio Del Rio-Hortega is credited with early insights into microglial pathology. He recognized that microglia are normally highly ramified and evenly distributed throughout the brain. He also noted that the morphology of microglia is dramatically altered in response to central nervous system (CNS) pathology [5]. As a molecular and functionally unique population of cells $[6,7]$, microglia exhibit a remarkable ability to survey the brain and rapidly undergo a spectrum of responses to insults or tissue damage $[8,9]$. The process by which microglia change shape, molecular signature, and cellular physiology is defined as microglia activation [5].

The clinical disease formerly referred to simply as "Alzheimer's disease" is, at the population level, a complex manifestation of many different brain conditions [10]. These age-related brain pathologies include AD (characterized by amyloid plaques and neurofibrillary tangles), as well as cerebrovascular disease, dementia with Lewy bodies (DLB), and hippocampal sclerosis of aging (HS-Aging) [11]. Although each of these disorders seems to have a distinct genetic, clinical, and pathological cluster of characteristics, to date there has not been characterization of the microglial responses in these conditions.

We sought to address questions related to microglial morphology in neurodegenerative disease tissue: 1) Is microglia pathology seen only in the presence of amyloid or tau pathology, or can it be seen in other age-related neurodegenerative diseases?; 2) Is there microglial regional heterogeneity in the hippocampus (for example, gray matter only)?; and, 3) Can digital neuropathological quantification detect differences in microglia activation in different neurodegenerative diseases? To address these questions, we queried well-characterized brain samples from the University of Kentucky Alzheimer's Disease Center (UK-ADC) cohort. Specifically, brain tissue was analyzed, incorporating multiple disease conditions, using two antibodies that react with microglia. The CD68 antibody stains for a lysosomal-associated protein in macrophages/microglia and is associated with phagocytic cells [12, 13]. The IBA1 (ionized calcium binding adaptor molecule 1) antibody [14] is used widely as a pan marker for both resting and activated microglia. Using these two widely studied microglia markers, CD68 and IBA1, we defined microglia morphologies in the aged brain, including some features that show evidence of disease specificity.

\section{Materials and methods Human subjects}

Tissue samples that contained the hippocampus were acquired from the UK-ADC biobank. Details of recruitment have been described previously [15]. Information including demographic and neuropathologic data is presented (Table 1). The included cases $(n=39)$ represented a convenience sample subdivided into groups as: NC, HS-aging, $\mathrm{AD}, \mathrm{AD}+\mathrm{HS}$-aging, or DLB. Cases represented approximately age-matched sampling of the neuropathologicallydefined diseases using the following criteria: AD (Braak > IV, high density of neocortical amyloid plaques); isocortical subtype of DLB; and HS-Aging (cell loss and gliosis out of proportion to plaques/tangle pathology, with TDP-43 pathology in the hippocampus).

\section{Immunostaining}

Paraffin-embedded tissue sections were cut at $10-\mu \mathrm{m}$-thick. Immunohistochemical (IHC) began with microwave antigen retrieval for 6 min (power 8) using Trilogy buffer (Cell Marque; Rocklin, CA) for CD68 and Declere buffer (Cell Marque; Rocklin, CA) for IBA1. Sections were then placed in $3 \% \mathrm{H}_{2} \mathrm{O}_{2}$ in methanol for $30 \mathrm{~min}$. Following washes in distilled water, sections were blocked in $5 \%$ goat serum at room temperature for $1 \mathrm{~h}$. Sections were incubated in primary antibodies IBA1 (rabbit polyclonal, 1:1,000 IHC, Wako); CD68 (clone KP1) (1:50 IHC, Dako) overnight at $4^{\circ} \mathrm{C}$. A biotinylated secondary antibody (Vector Laboratories) was amplified using avidin-biotin substrate (ABC solution, Vector Laboratories catalog no. PK-6100), followed by color development in Nova Red (Vector Laboratories). Immunofluorescence (IF) staining was done following microwave antigen retrieval for $6 \mathrm{~min}$ (power 8) using Declere buffer (Cell Marque; Rocklin, CA) for primary antibodies to: IBA1 (rabbit polyclonal, 1:250 IF, Wako); and PHF-1 (1:500 IHC and IF, a kind gift from Dr Peter Davies, Bronx, NY), and visualized using appropriate secondary antibody conjugated to an Alexafluor probe (1:200, Lifetechnologies) applied for $1 \mathrm{~h}$. A $0.1 \%$ solution of Sudan Black was used to reduce autofluorescence. Slides were coverslipped using Vectashield mounting medium with DAPI (Vector Labs, Burlingame, CA).

\section{Quantitative image analysis}

Three different methods of quantitative image analysis were used in this study: 1) digital positive pixel algorithm, 2) digital nuclear algorithm, 3) and manual counting of $\mathrm{IBA}^{+}$microglia (only in CA1 region). Briefly, the Aperio ScanScope XT digital slidescanner was used to image the entire stained slide at 40x magnification to create a single high-resolution digital image. The Aperio positive pixel count algorithm (version 9) was used to quantify the amount of specific staining in the region, and the Aperio nuclear algorithm (version 9) was used to determine the number of stained microglia 
Table 1 Cohort demographics and numbers

\begin{tabular}{|c|c|c|c|c|c|c|c|c|c|c|c|}
\hline case & $\begin{array}{l}\text { age at } \\
\text { death }\end{array}$ & $\begin{array}{l}\text { Final } \\
\text { MMSE }\end{array}$ & sex & $\begin{array}{l}\text { ApoE } \\
\text { alleles }\end{array}$ & $\begin{array}{l}\text { PMl } \\
\text { (h) }\end{array}$ & $\begin{array}{l}\text { Braak } \\
\text { stage }\end{array}$ & $\begin{array}{l}\text { CERAD plaque } \\
\text { stage }\end{array}$ & $\begin{array}{l}\text { diffuse } \\
\text { plaques }\end{array}$ & $\begin{array}{l}\text { neuritic } \\
\text { plaques }\end{array}$ & NFTs & $\begin{array}{l}\text { diff } \\
\text { boc }\end{array}$ \\
\hline \multicolumn{12}{|c|}{$\overline{N C}=$ non-demented control: mean age $=86 ;$ mean $\mathrm{MMSE}=30 ;$ Median Braak stage $=2 ;$ Median CERAD $=0$} \\
\hline 1 & 81 & 30 & M & $3 / 3$ & 2.17 & 2 & 0 & 0 & 0 & 0 & 0 \\
\hline 2 & 91 & 30 & M & $\mathrm{n} / \mathrm{a}$ & $\mathrm{n} / \mathrm{a}$ & 2 & 0 & 0 & 0 & 1.4 & 0 \\
\hline 3 & 86 & 30 & $M$ & $3 / 3$ & 2.17 & 3 & 0 & 0 & 0 & 4.6 & 0 \\
\hline 4 & 93 & 30 & $F$ & $3 / 3$ & 2.25 & 2 & 0 & 0 & 0 & 0.25 & 0 \\
\hline 5 & 84 & 30 & $M$ & $2 / 3$ & 3.25 & 0 & 0 & $\mathrm{n} / \mathrm{a}$ & $\mathrm{n} / \mathrm{a}$ & $\mathrm{n} / \mathrm{a}$ & 0 \\
\hline 6 & 85 & 30 & $M$ & $3 / 3$ & 2 & 3 & 1 & 2 & 0.5 & 8 & 0 \\
\hline 7 & 84 & 30 & F & $3 / 3$ & 2.42 & 0 & 0 & 0 & 0 & 0 & 0 \\
\hline 8 & 92 & 30 & $\mathrm{~F}$ & $2 / 3$ & 3.25 & 3 & 2 & 5 & 0 & 0.75 & 0 \\
\hline 9 & 81 & 30 & $M$ & $3 / 4$ & 2 & 2 & 2 & 2 & 10.5 & 1 & 0 \\
\hline
\end{tabular}

$\mathrm{HS}=$ hippocampal sclerosis of aging: mean age $=87$; mean $\mathrm{MMSE}=22.7$; Median Braak stage $=2$; Median $C E R A D=0$

\begin{tabular}{|c|c|c|c|c|c|c|c|c|c|}
\hline $10 \quad 74$ & 20 & $M$ & $3 / 4$ & 8 & 3 & 2 & 0 & 0 & 1.4 \\
\hline 95 & 16 & $\mathrm{~F}$ & $3 / 4$ & 3.25 & 3 & 0 & 0 & 0 & 1 \\
\hline 87 & 28 & $F$ & $3 / 3$ & 1.82 & 3 & 0 & 0 & 0 & 4 \\
\hline 84 & 10 & $\mathrm{~F}$ & n/a & 2.57 & 2 & 0 & 0 & 0 & 0 \\
\hline 91 & 29 & $\mathrm{~F}$ & $2 / 3$ & 2.87 & 2 & 1 & 0 & 0 & 6.8 \\
\hline 91 & 30 & $M$ & $3 / 3$ & 2.83 & 2 & 0 & n/a & $\mathrm{n} / \mathrm{a}$ & $\mathrm{n} / \mathrm{a}$ \\
\hline 88 & 26 & $M$ & $3 / 4$ & 2.33 & 0 & 0 & 0 & 0 & 0 \\
\hline
\end{tabular}

$\mathrm{AD}=$ Alzheimer's disease: mean age $=77$; mean $\mathrm{MMSE}=11$; Median Braak stage $=6$; Median $\mathrm{CERAD}=3$

\begin{tabular}{|c|c|c|c|c|c|c|c|c|c|}
\hline $17 \quad 75$ & 18 & $\mathrm{~F}$ & $3 / 4$ & 2.5 & 6 & 3 & 9 & 0.33 & 25 \\
\hline 84 & 13 & $M$ & $4 / 4$ & 5.17 & 6 & 3 & 4 & 1.33 & 26.75 \\
\hline 65 & 3 & $\mathrm{~F}$ & $3 / 4$ & 4.1 & 6 & 3 & 2.67 & 1.67 & 41 \\
\hline 85 & 4 & F & $3 / 3$ & 11.2 & 6 & 3 & 6.67 & 1.33 & 78.8 \\
\hline 79 & 6 & M & $\mathrm{n} / \mathrm{a}$ & 2.08 & 6 & 3 & 4.33 & 2.33 & 25.6 \\
\hline 67 & 11 & $M$ & $2 / 3$ & 1.75 & 6 & 3 & 0.33 & 0 & 2.4 \\
\hline 82 & 25 & $M$ & $\mathrm{n} / \mathrm{a}$ & 2.75 & 6 & 2 & 1.67 & 2.67 & 19.8 \\
\hline
\end{tabular}

$\mathrm{AD}+\mathrm{HS}$ : mean age $=91 ;$ mean $\mathrm{MMSE}=7.8 ;$ Median Braak stage $=6$; Median $\mathrm{CERAD}=3$

\begin{tabular}{|c|c|c|c|c|c|c|c|c|c|}
\hline $24 \quad 96$ & 6 & $\mathrm{~F}$ & $3 / 3$ & 6.75 & 6 & 3 & $\mathrm{n} / \mathrm{a}$ & $\mathrm{n} / \mathrm{a}$ & $\mathrm{n} / \mathrm{a}$ \\
\hline 91 & 13 & $\mathrm{~F}$ & $3 / 3$ & 3 & 5 & 3 & 6.67 & 1.33 & 34 \\
\hline 91 & 12 & $F$ & $4 / 4$ & 2.33 & 6 & 3 & 0 & 0 & 10.25 \\
\hline 87 & 0 & $\mathrm{~F}$ & $3 / 3$ & 2.67 & 6 & 3 & 0 & 0 & 54.6 \\
\hline
\end{tabular}

$\mathrm{DLB}=$ Dementia with Lewy bodies: mean age $=80$; mean MMSE $=17.25$; Median Braak stage $=2 ;$ Median CERAD $=1$

\begin{tabular}{|c|c|c|c|c|c|c|c|c|c|}
\hline 28 & 9 & $M$ & $4 / 4$ & 9.5 & 2 & 3 & 2 & 7.67 & 2 \\
\hline 61 & 18 & $M$ & $3 / 3$ & 2 & 2 & 0 & 0 & 0 & 9.6 \\
\hline 85 & 2 & $\mathrm{~F}$ & $2 / 3$ & 2 & 2 & 3 & 4 & 6.67 & 3.6 \\
\hline 85 & 27 & $M$ & $3 / 3$ & 11.2 & 2 & 1 & 0 & 0 & 0.8 \\
\hline 89 & 27 & $M$ & $3 / 3$ & 2.42 & 2 & 0 & 0 & 0 & 8.5 \\
\hline 92 & 27 & $\mathrm{~F}$ & $3 / 4$ & 2.42 & 2 & 1 & 0.67 & 0 & 2 \\
\hline 68 & 11 & $M$ & $3 / 4$ & 3.75 & 2 & 2 & 0 & 0 & 0.4 \\
\hline 81 & 15 & $M$ & $3 / 3$ & 2.42 & 2 & 2 & 1.5 & 2.5 & 0.25 \\
\hline 78 & 9 & $M$ & $3 / 3$ & 2.5 & 1 & 0 & 0 & 0 & 2 \\
\hline 81 & 26 & $M$ & $3 / 3$ & 5.77 & 1 & 1 & 0 & 0 & 0 \\
\hline 97 & 21 & $M$ & $2 / 3$ & 3.5 & 1 & 0 & 0 & 0 & 1.8 \\
\hline
\end{tabular}


Table 1 Cohort demographics and numbers (Continued)

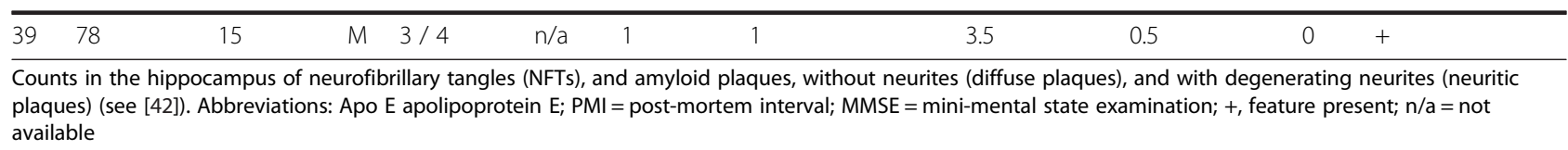

as previously described $[16,17]$. The number of IBA $1^{+}$ microglia was counted by morphological appearance in 5 arbitrarily placed $250 \times 250 \mu \mathrm{m}$ boxes in the CA1 region. A researcher (coauthor ADB) blind to all samples' case histories conducted all data analysis. Immunofluorescence was imaged using a Nikon Eclipse 90i upright microscope equipped with a Nikon DS-Ri1 digital camera.

\section{Statistics}

JMP Software version 10.0 was used for statistical analysis. Normality was assessed using the Shapiro-Wilk test. As there were only a few violations of normality, and ANOVA is robust to such violations [18], a one-way ANOVA followed by a Tukey post hoc analysis was used to compare differences between the five groups. Mean \pm SD for quantifications are shown in Table 2. Differences between means

Table 2 Summary of microglia neuropathological assessment

\begin{tabular}{|c|c|c|c|c|c|c|c|}
\hline \multicolumn{8}{|c|}{ CD68 positive pixels (Fig. 2) } \\
\hline & WM & sub & CA1 & $\mathrm{CA} 2 / 3$ & CA4 & DG & hipp ave \\
\hline $\mathrm{NC}(\mathrm{N}=9)$ & $7.5 \pm 4$ & $2.5 \pm 1.6$ & $2.6 \pm 2.2$ & $3.2 \pm 2.1$ & $2.8 \pm 2.2$ & $2.4 \pm 1.6$ & $3.5 \pm 2.1$ \\
\hline HS-aging $(\mathrm{N}=7)$ & $8.7 \pm 2.4$ & $6 \pm 3.5$ & $5.4 \pm 2.1$ & $4.1 \pm 2.1$ & $3.4 \pm 1.2$ & $2.4 \pm 1.2$ & $5 \pm 1.4$ \\
\hline $\mathrm{AD}(\mathrm{N}=7)$ & $10.6 \pm 3.2$ & $6.2 \pm 2$ & $5.3 \pm 1.5$ & $4.2 \pm 2.6$ & $3.5 \pm 1.2$ & $4.8 \pm 2$ & $5.8 \pm 1$ \\
\hline$A D+H S(N=4)$ & $8.7 \pm 3.6$ & $5.5 \pm 2.6$ & $5.8 \pm 2.1$ & $3.2 \pm 1.2$ & $2.4 \pm 1.3$ & $2.5 \pm 1.4$ & $4.7 \pm 1.2$ \\
\hline $\operatorname{DLB}(\mathrm{N}=12)$ & $7.6 \pm 2.8$ & $2.7 \pm 1$ & $2.3 \pm 0.8$ & $3.4 \pm 2.3$ & $2.7 \pm 1.1$ & $2.2 \pm 0.3$ & $3.5 \pm 0.9$ \\
\hline \multicolumn{8}{|c|}{ CD68 nuclear algorithm (Fig. 4) } \\
\hline$N C(N=9)$ & $54.7 \pm 52.1$ & $13.9 \pm 17.9$ & $16 \pm 18.5$ & $17 \pm 18.3$ & $20 \pm 24$ & $10.7 \pm 11.3$ & $22.1 \pm 22.1$ \\
\hline HS-aging $(\mathrm{N}=7)$ & $54.8 \pm 45.1$ & $34.4 \pm 33.6$ & $30.2 \pm 20.9$ & $20.4 \pm 19.8$ & $19.2 \pm 11.9$ & $8.1 \pm 7.8$ & $27.8 \pm 21.2$ \\
\hline $\mathrm{AD}(\mathrm{N}=7)$ & $100.2 \pm 68.4$ & $45.8 \pm 35.8$ & $29.2 \pm 16.8$ & $16.4 \pm 7.5$ & $17.3 \pm 13.3$ & $26.3 \pm 18.1$ & $39.2 \pm 22.4$ \\
\hline $\mathrm{AD}+\mathrm{HS}(\mathrm{N}=4)$ & $32.4 \pm 15.8$ & $27.2 \pm 22.4$ & $28.7 \pm 26.6$ & $15.4 \pm 14.4$ & $8 \pm 6.8$ & $3.8 \pm 5.2$ & $19.2 \pm 13.7$ \\
\hline $\operatorname{DLB}(\mathrm{N}=12)$ & $53.3 \pm 35$ & $11.8 \pm 9$ & $11.6 \pm 7.7$ & $15.6 \pm 11.1$ & $13.3 \pm 8.1$ & $8.9 \pm 5.9$ & $19.1 \pm 10.1$ \\
\hline \multicolumn{8}{|c|}{ IBA1 nuclear algorithm (Fig. 5) } \\
\hline$N C(N=9)$ & $101.9 \pm 30.2$ & $66.5 \pm 14.3$ & $60.8 \pm 22.9$ & $74 \pm 11.7$ & $82.7 \pm 16.8$ & $80.5 \pm 18.7$ & $77.7 \pm 11.7$ \\
\hline HS-aging $(\mathrm{N}=7)$ & $143.7 \pm 80.8$ & $84.7 \pm 39.4$ & $122.1 \pm 63.5$ & $142.8 \pm 37.3$ & $110.9 \pm 50.3$ & $92.3 \pm 39.1$ & $116.1 \pm 45.4$ \\
\hline $\mathrm{AD}(\mathrm{N}=7)$ & $87.8 \pm 55.4$ & $84.1 \pm 44.2$ & $64.2 \pm 16.2$ & $75.5 \pm 19.2$ & $43.2 \pm 27.2$ & $50.5 \pm 37.2$ & $67.5 \pm 26.7$ \\
\hline$A D+H S(N=4)$ & $97.9 \pm 25.8$ & $116.4 \pm 74.9$ & $108.2 \pm 42.1$ & $132.4 \pm 64.6$ & $94.3 \pm 47.1$ & $98.9 \pm 47.1$ & $108 \pm 41.9$ \\
\hline $\mathrm{DLB}(\mathrm{N}=12)$ & $103.2 \pm 55.6$ & $69.3 \pm 35.6$ & $70 \pm 32$ & $74.2 \pm 46.7$ & $83.8 \pm 48$ & $74.5 \pm 43.9$ & $79.2 \pm 40.7$ \\
\hline \multicolumn{8}{|c|}{ IBA1 positive pixels (Fig. 6) } \\
\hline$N C(N=9)$ & $2.8 \pm 0.8$ & $2.6 \pm 0.9$ & $2.4 \pm 0.7$ & $3.1 \pm 0.8$ & $3.3 \pm 1$ & $3.1 \pm 0.8$ & $2.9 \pm 0.7$ \\
\hline HS-aging $(\mathrm{N}=7)$ & $4 \pm 1.8$ & $2.5 \pm 0.9$ & $3.2 \pm 1.1$ & $3.9 \pm 0.8$ & $3.5 \pm 1.3$ & $3.1 \pm 1.1$ & $3.3 \pm 1$ \\
\hline$A D(N=7)$ & $2.7 \pm 1.2$ & $2.5 \pm 1.1$ & $2.2 \pm 0.6$ & $3.1 \pm 1$ & $2 \pm 1.1$ & $2.1 \pm 0.8$ & $2.4 \pm 0.7$ \\
\hline $\mathrm{AD}+\mathrm{HS}(\mathrm{N}=4)$ & $3.6 \pm 0.8$ & $3.4 \pm 2.1$ & $3.6 \pm 1.1$ & $3.9 \pm 1.2$ & $3.1 \pm 0.7$ & $3.3 \pm 1$ & $3.5 \pm 1$ \\
\hline $\operatorname{DLB}(N=12)$ & $2.8 \pm 0.8$ & $1.9 \pm 0.6$ & $1.9 \pm 0.5$ & $2.3 \pm 0.8$ & $2.6 \pm 0.9$ & $2.5 \pm 0.9$ & $2.3 \pm 0.7$ \\
\hline \multicolumn{8}{|c|}{ Morphological assessment of $\mid \mathrm{BA} 1^{+}$microglia in CA1 region (Fig. 7) } \\
\hline & ramified & hypertrophic & dystrophic & rod-shaped & amoeboid & total & \\
\hline$N C(N=9)$ & $16.9 \pm 9.8$ & $3.7 \pm 7.1$ & $4.4 \pm 3.9$ & $2.1 \pm 4.1$ & $3.7 \pm 5$ & $30.8 \pm 10.3$ & \\
\hline HS-aging $(\mathrm{N}=7)$ & $2.6 \pm 2.6$ & $13.8 \pm 11.9$ & $32.2 \pm 22$ & $2.4 \pm 5.1$ & $8.8 \pm 8.8$ & $59.9 \pm 29.8$ & \\
\hline $\mathrm{AD}(\mathrm{N}=7)$ & $19.7 \pm 10.4$ & $4.5 \pm 6.1$ & $11.2 \pm 9.7$ & $2.6 \pm 2.7$ & $4.5 \pm 3.6$ & $42.4 \pm 11.5$ & \\
\hline $\mathrm{AD}+\mathrm{HS}(\mathrm{N}=4)$ & $9.8 \pm 8.3$ & $20.2 \pm 13.7$ & $19.8 \pm 11.2$ & $2.6 \pm 3.2$ & $14.6 \pm 12.4$ & $67 \pm 15.8$ & \\
\hline DLB $(N=12)$ & $9.3 \pm 6.5$ & $2.5 \pm 3.6$ & $13.9 \pm 9.3$ & $3.9 \pm 4$ & $1.9 \pm 2.6$ & $31.3 \pm 8.2$ & \\
\hline
\end{tabular}


were considered significant at $p<0.05$. Heatmaps were generated using JMP Software version 10.0. All other graphs were generated using GraphPad Prism software version 6.0, with values expressed as mean \pm SEM.

\section{Results}

Five groups of cases (Table 1$)$ were pathologically-confirmed as either $\mathrm{AD}(n=7)$, HS-Aging $(n=7), \mathrm{AD}+\mathrm{HS}$-aging $(n=$ $4)$, DLB $(n=12)$, and NC $(n=9)$. HS-aging and DLB cases were included in this study to determine if there is disease specificity in microglia pathology and to provide the first quantitative analysis of microglia in HS-Aging. Pure HS-aging cases lacked substantial additional pathologies AD-type pathology, or Lewy bodies [19-21], as shown in Table 1 . The neuropathological changes associated with neocortical/diffuse Lewy body disease include, by definition, $\alpha$-synuclein immunoreactive neuronal inclusions (Lewy bodies) and processes in multiple portions of the cerebral neocortex. In pure DLB, there are low levels of amyloid- $\beta$ pathology or NFTs, as shown in Table 1.

Primary goals of this study were to assess regional microglia heterogeneity and to exploit the ability of digital neuropathological quantification to detect in differences microglial morphometry when cases are stratified according to their neurodegenerative diseases. Six regions of interest (ROI) were identified by dividing the hippocampal formation into the dentate gyrus (DG), the cornu ammonis (CA) areas (CA1, CA2/3, and CA4), the subiculum (sub), and the adjacent white matter (WM) (Fig. 1). Representative examples of the ROIs are shown in Fig. 1.

\section{Pattern of CD68 staining in the hippocampus of autopsy cases}

Quantification of the CD68 positive pixels is shown in Fig. 2. By a one-way ANOVA a significant effect of disease status was found sub (Fig. 2c; $\mathrm{F}_{4,38}=6.3001 ; p=$ 0.0007), CA1 (Fig. 2d; $F_{4,38}=8.0944 ; p<0.001$ ), DG

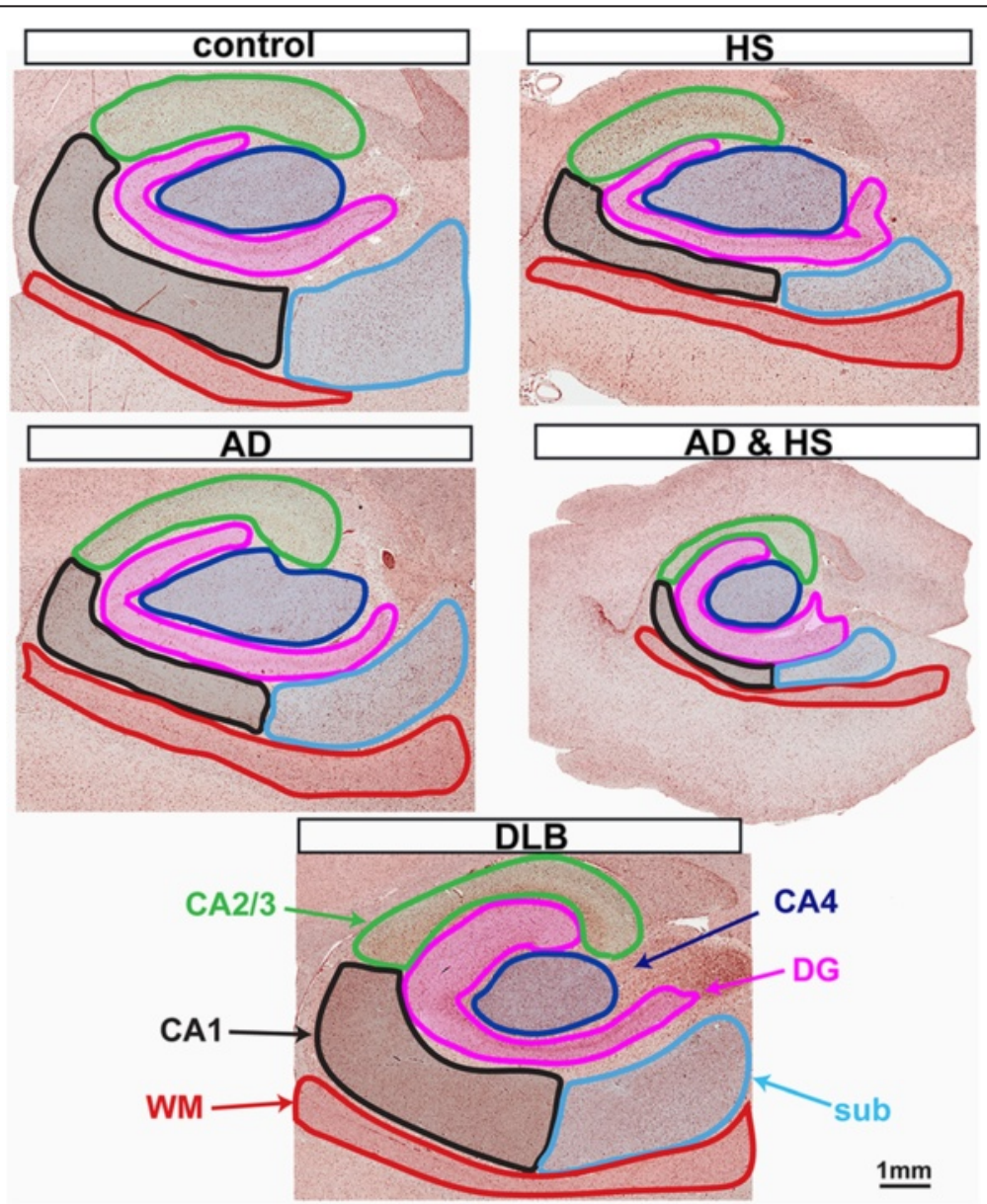

Fig. 1 Regions of interest used for microglia analysis. A representative hippocampus is shown for the five neuropathological diagnoses included in this study. The outlines illustrate the boundaries used in identifying the following brain regions: white matter (WM), subiculum (sub), the cornu ammonis (CA) areas, CA1, CA2/3, CA4, and the dentate gyrus (DG). The ROls shown in the figure are not the actual ROls used for analysis, as some of the ROls (WM and sub) could not be included in the image frame, as the brain region was larger than the image frame 


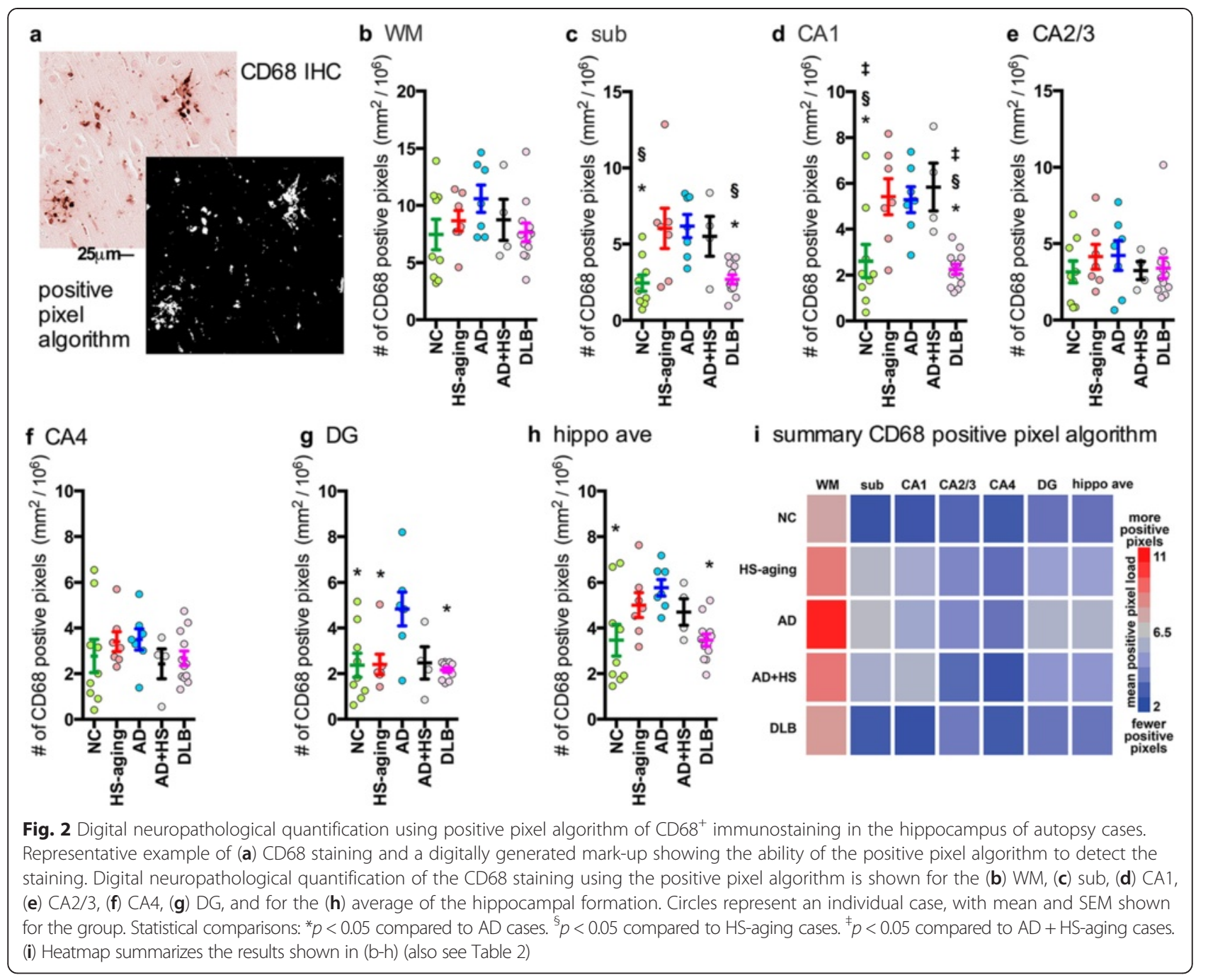

(Fig. 2g; $\mathrm{F}_{4,38}=5.3332 ; \mathrm{p}=0.0019$ ), and in the average of the six regions in the hippocampus formation (Fig. 2h; $\mathrm{F}_{4,38}=4.3221 ; \mathrm{p}=0.0062$ ). No significant effect was found by a one-way ANOVA in WM (Fig. 2b), CA2/3, (Fig. 2e), or CA4 (Fig. 2f). HS-aging, AD, and $\mathrm{AD}+\mathrm{HS}$-aging were found to have significantly more $\mathrm{CD}^{+} 8^{+}$staining in the CA1 region compared to $\mathrm{NC}$ or DLB cases (Fig. 2d). However, there was no significant difference among the three disease conditions (HSaging, $\mathrm{AD}$, and $\mathrm{AD}+\mathrm{HS}$-aging) in the $\mathrm{CA} 1$ region (Fig. 2d). Interestingly, we found significantly more $\mathrm{CD} 68^{+}$staining in the DG of AD cases compared to the other four groups (Fig. 2g). When averaged across the six-hippocampal formation sub regions, the AD cases were found to have significantly more $\mathrm{CD}^{+} 8^{+}$staining compared to NC or DLB groups. Overall, the greatest $\mathrm{CD}^{+} 8^{+}$staining was seen in the WM, as is evident by the heatmap summary of the CD68 positive pixel analysis (Fig. 2i). A survey of the $\mathrm{CD}^{+} 8^{+}$staining in the six-hippocampal formation regions illustrates the regional and disease-specific heterogeneity in the staining (Fig. 3). Of note is a large round cell type that can be found in areas of high density staining as shown in Fig. 3b-c. Interestingly, just distal to the very intense accumulation of $\mathrm{CD}^{+} 8^{+}$cells, the $\mathrm{CD}^{+} 8^{+}$staining was unremarkable, with a few ramified microglia (Fig. 3d). Quantification of the number of large round CD68 ${ }^{+}$ cells was done using the nuclear algorithm, by adjusting the algorithm to detect only the large round cells as shown in Fig. 4. In comparison to design based stereological methods, limitations of the nuclear algorithm include an inability to provide an estimate of the total number of microglia, because of a lack of 3dimensional volume measurements [22, 23]. Limitations notwithstanding, results of the nuclear algorithm were similar to the positive pixel algorithm, with the HS-aging and AD groups having the greatest number of $\mathrm{CD} 8^{+}$cells (Table 2). As shown by the heatmap, the greatest number of $\mathrm{CD}^{+} 8^{+}$cells was found in the WM of AD cases (Fig. 4). 


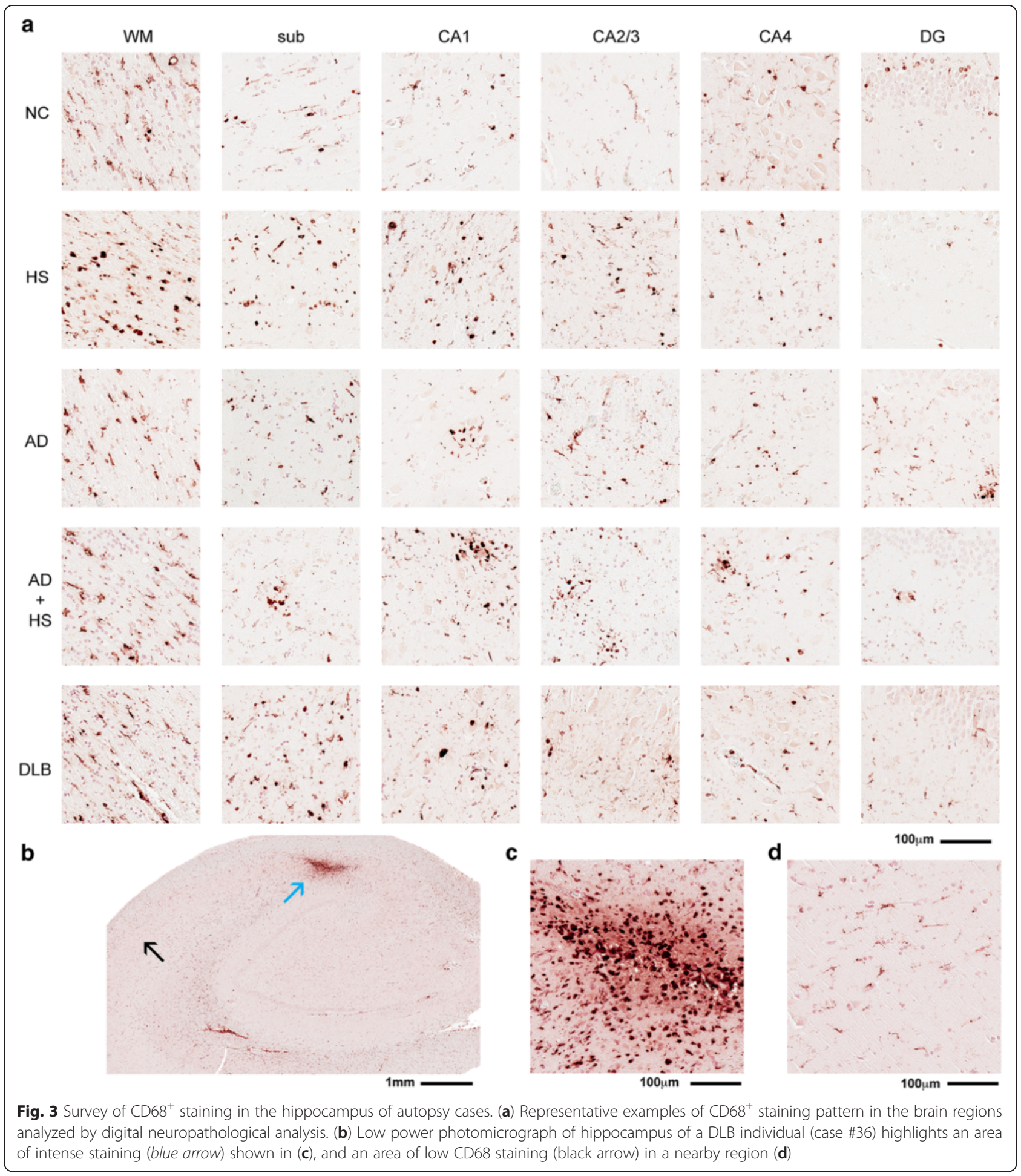

\section{Digital quantification of IBA1 staining in the hippocampus of autopsy cases}

Quantification of the number of IBA $1^{+}$cells by the nuclear algorithm is shown in Fig. 5. A representative example of the ability of the algorithm to detect individual cells is shown in Fig. 5a. By a one-way ANOVA, a significant effect of disease status was found in the CA1 region (Fig. 5d; $\left.\mathrm{F}_{4,38}=3.9914 ; p=0.0092\right), \mathrm{CA} 2 / 3$ region $\left(\right.$ Fig. $5 \mathrm{e} ; \mathrm{F}_{4,38}=$ 5.8525; $p=0.0011$ ), and in the CA4 (Figure $5 \mathrm{f}_{4,38}=$ 2.6929; $p=0.0473)$. No significant effect was found by a one-way ANOVA in WM (Figure 5b), sub (Fig. 5c), DG (Fig. $5 \mathrm{~g}$ ), or in the average of the six regions in the 


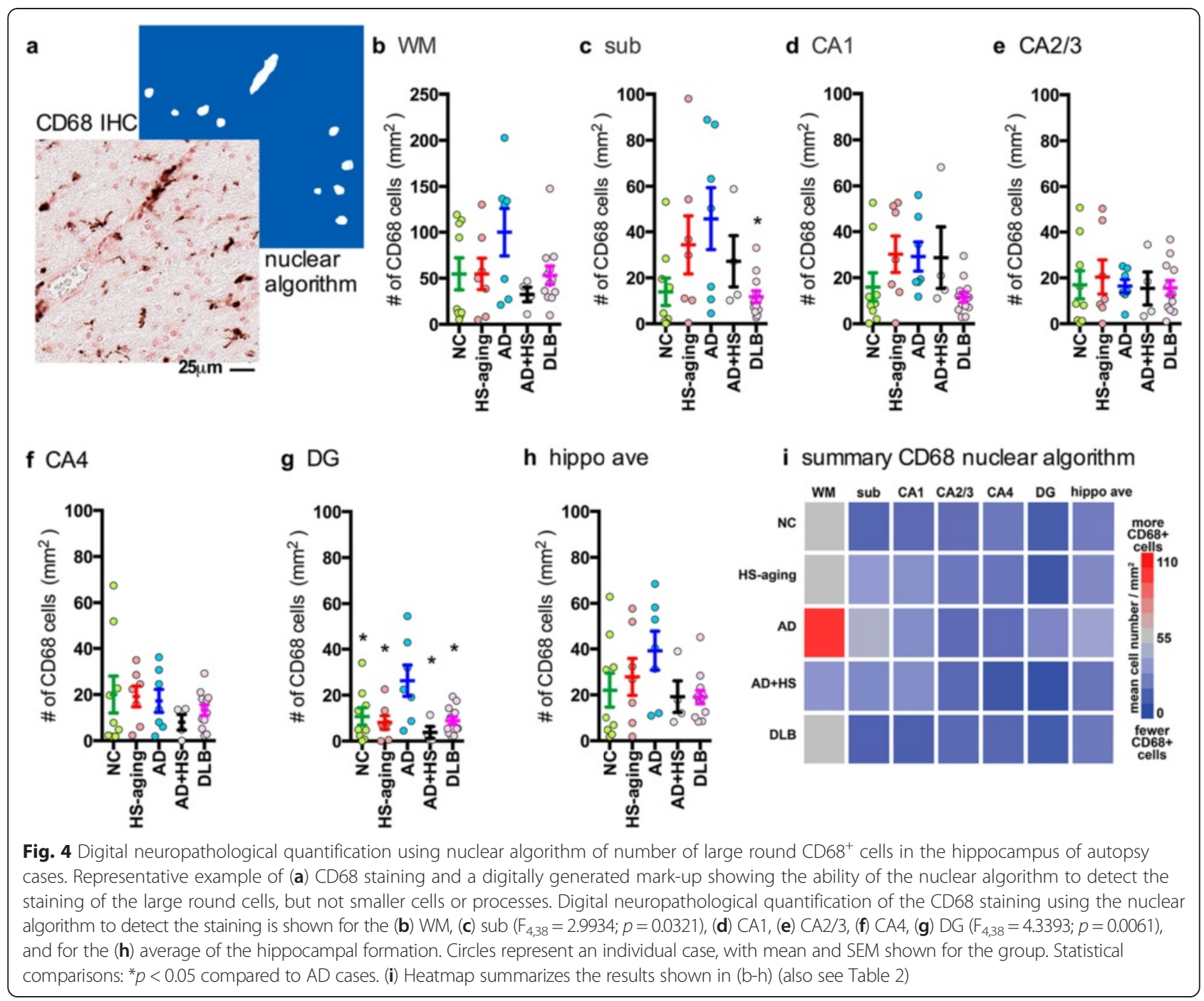

hippocampus formation (Fig. 5h). In the CA1 region, the $\mathrm{HS}$-aging had an increased number of $\mathrm{IBA}^{+}$cells compared to NC, AD or DLB. As shown by the heatmap summary, a similar pattern of increased number of $\mathrm{IBA}^{+}$ microglia was found in the HS-aging and AD + HS-aging groups compared to the $\mathrm{NC}, \mathrm{AD}$, or $\mathrm{DLB}$ groups (Fig. 5i). Quantification of the IBA1 positive pixels (Table 2) also showed a similar pattern of increased $\mathrm{IBA}^{+}{ }^{+}$staining in the HS-aging and $\mathrm{AD}+\mathrm{HS}$-aging groups compared to the NC, AD, or DLB groups (Fig. 6).

\section{$\mathrm{IBA} 1^{+}$microglia morphology in the hippocampus of autopsy cases}

An examination (Fig. 7a) of the $\mathrm{IBA}^{+}$microglia in the six ROIs in the five neuropathologic groups showed remarkable heterogeneity in microglia density, as captured by the digital neuropathological quantification. There was also heterogeneity in $\mathrm{IBA}^{+}$microglia morphology, which was underappreciated in the digital neuropathological analysis, as microglia density and cell number were measured irrespective of the microglia morphology. For example, a striking pattern of $\mathrm{IBA}^{+}$microglia morphology is the rod-shaped microglia, which were readily apparent in a subset of cases. As shown in Fig. 7b-c, rod-shaped microglia are characterized by a narrow cell body with a few planar processes. The rod-shaped microglia could be found as individual cells (Fig. 7b), or as long and thin groups of cells that may have fused (Fig. 7b and c and Fig. 8). The appearance of microglia with polarized and parallel processes suggested that the microglia could be following neurites-possibly, degenerating axons or neurons themselves. To test the possibility that microglia could be surrounding degenerating neuronal processes, double label immunofluorescence was performed for microglia (IBA1) and NFTs (PHF1). Fig. 8a shows abundant $\mathrm{PHF}^{+}$staining and $\mathrm{IBA}^{+}$rod-shaped microglia in the CA1 region of an $\mathrm{AD}$ individual (case \#23). We found no evidence of systematic overlap of $\mathrm{PHF}^{+}$neurites and $\mathrm{IBA}^{+}$rod-shaped microglia, as shown in Fig. 8b. Rather, 


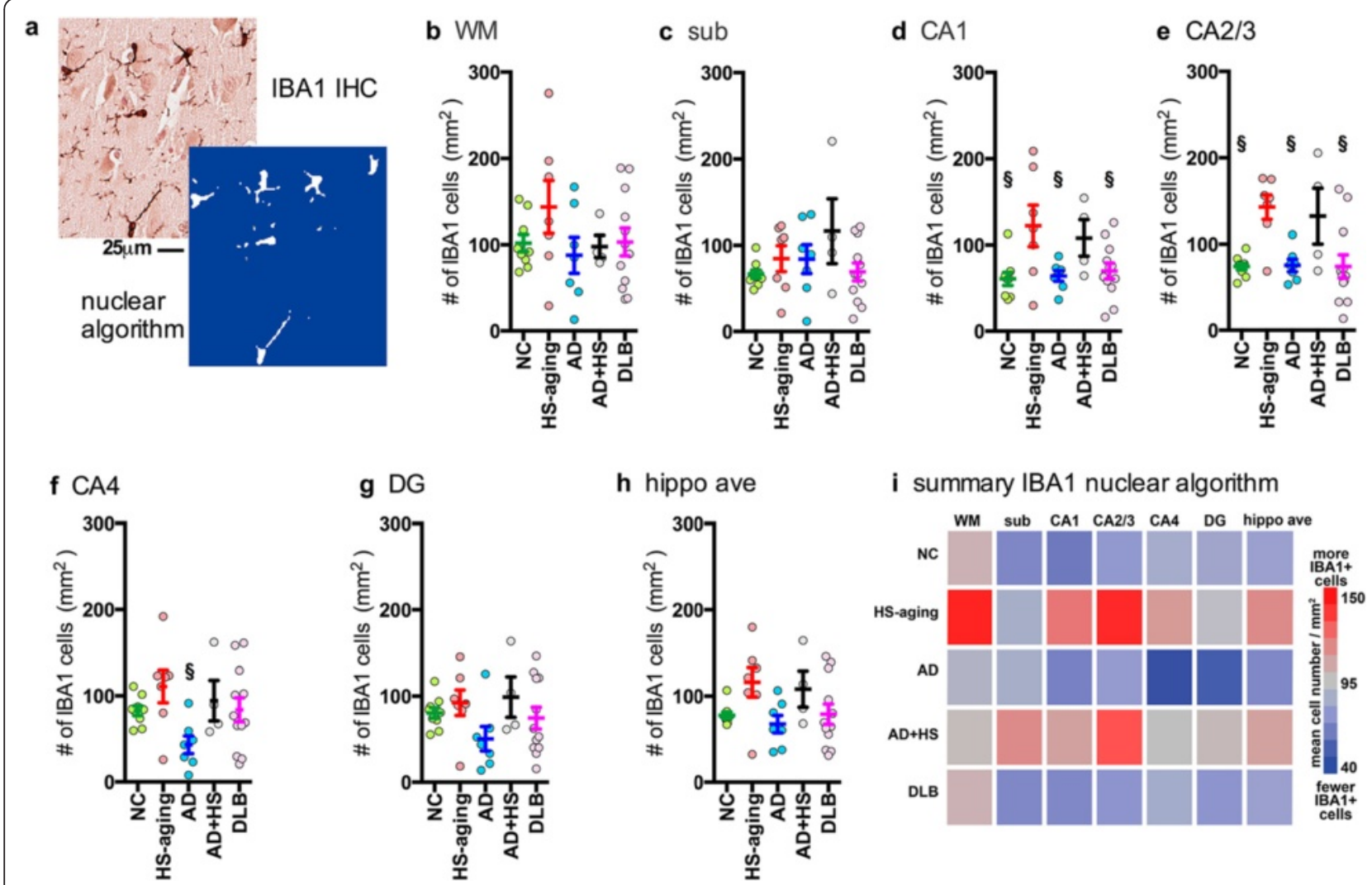

Fig. 5 Digital neuropathological quantification using nuclear algorithm of number of IBA $1^{+}$cells in the hippocampus of autopsy cases. Representative example of (a) IBA1 staining and a digitally generated mark-up showing the ability of the nuclear algorithm to detect six stained cells. Digital neuropathological quantification of the IBA1 staining using the nuclear algorithm is shown for the (b) WM, (c) sub, (d) CA1, (e) CA2/ 3, (f) CA4, (g) DG, and for the (h) average of the hippocampal formation.. Circles represent an individual case, with mean and SEM shown for the group. Statistical comparisons: ${ }^{\S} p<0.05$ compared to HS-aging cases. (i) Heatmap summarizes the results shown in (b-g) (also see Table 2)

long trains of rod-shaped microglia could sometimes be seen to run parallel to and between $\mathrm{PHF}^{+}$neurons but did not co-localize with the PHF1 ${ }^{+}$staining (Fig. 8c). In this example, the tip of the rod-shaped microglia was near (but not within) a PHF1 ${ }^{+}$structure, and the IBA-1 immunoreactive structure appeared to be a fusion / cluster of multiple cells with 5 clearly visible DAPI ${ }^{+}$nuclei (Fig. 8d).

Another pattern of microglia morphology observed was the dystrophic / degenerating microglia, which overlapped morphologically with cells that have been described to have processes that are spheroidal, beaded, de-ramified, or fragmented [24, 25]. Examples of dystrophic / degenerating microglia are shown in Fig. 9. In AD (Fig. 9a) and DLB (Fig. 9b), for example, the dystrophic / degenerating microglia had very thin processes that are beaded and fragmented. In HS-aging (Fig. 9c) and AD+HS-aging (Fig. 9d), dystrophic microglia morphology was more striking, and the processes of the microglia were beaded and tortuous.

The remarkable diversity in the microglia morphology led us to carefully review and categorize the morphological appearances of the microglia into five distinct classes
(Fig. 10a), to allow measurement of changes in the microglia classes associated with the five neurodegenerative disease groups. The five classes of microglia morphologies included: 1) ramified microglia, which have a 'surveying' non-reactive microglia morphological appearance, with thin highly branched processes [5, 26]; 2) hypertrophic microglia (often called activated microglia), which have become enlarged, hyper-ramified or may have short thick processes [5, 26]; 3) dystrophic microglia, with processes that are spheroidal, beaded, de-ramified, or fragmented [24-26]; 4) rodshaped microglia, characterized by a narrow cell body with a few planar processes [27, 26]; and 5) amoeboid microglia, with an enlarged cell body with few to no processes $[5,26]$. CD68 staining could clearly identify cells with an amoeboid morphology, and to a lesser extent cells with a ramified morphology. In contrast, IBA1 staining was useful to identify all five microglia morphologies. Therefore, IBA1 staining was used to quantify the distribution in the microglia morphology according to these five subtypes of microglial shapes. Focusing on the CA1 region of the hippocampus, the number of each of the five morphological classes of $\mathrm{IBA}^{+}$microglia was counted in five randomly placed 

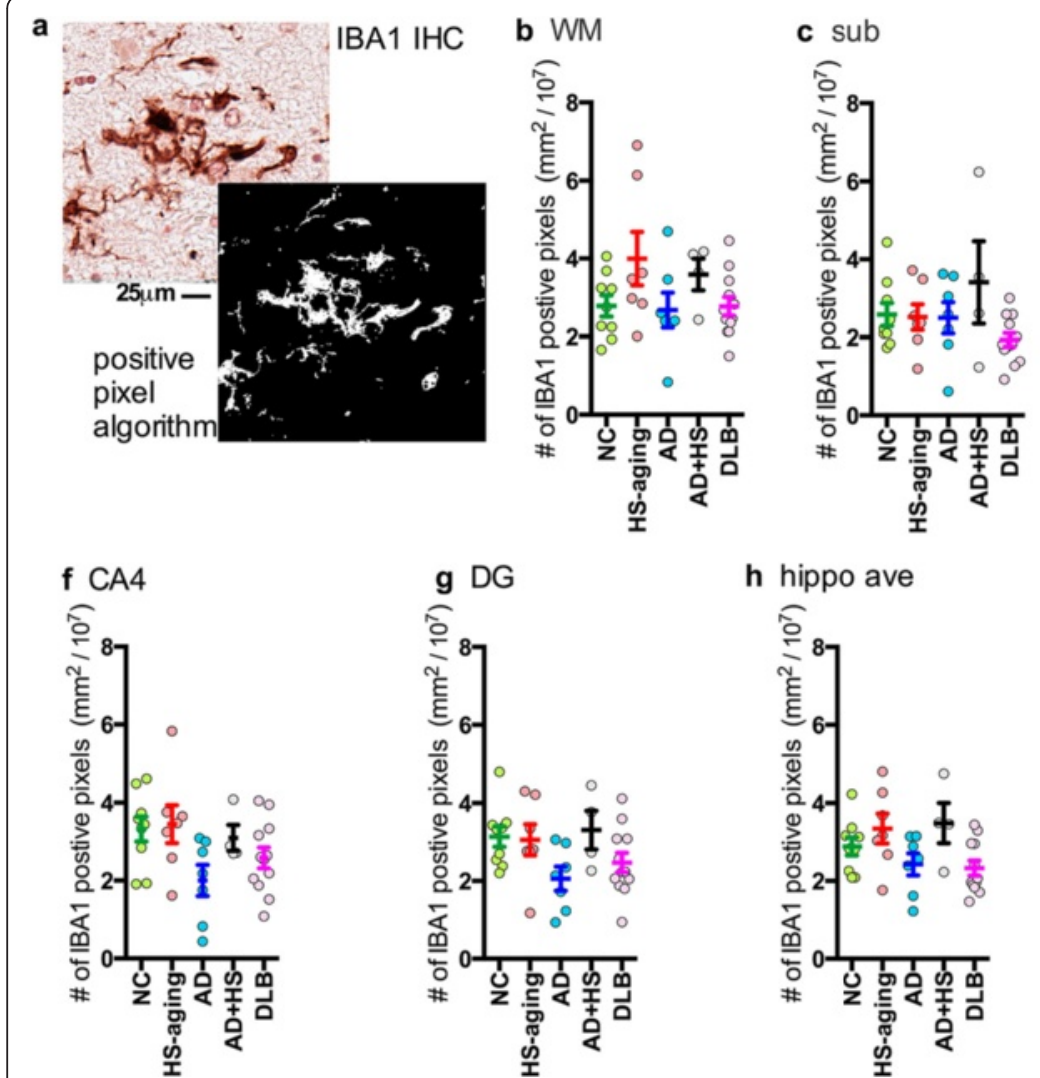

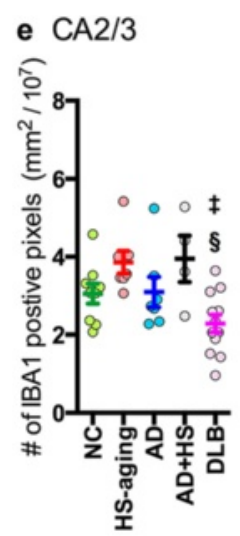

i summary IBA1 positive pixel algorithm

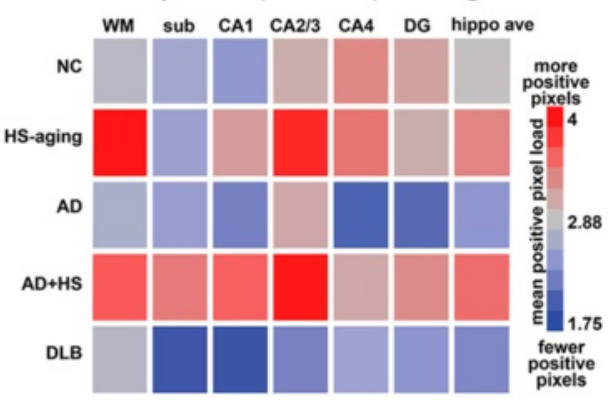

Fig. 6 Digital neuropathological quantification using positive pixel algorithm of IBA $1^{+}$immunostaining in the hippocampus of autopsy cases. Representative example of (a) IBA1 staining and a digitally generated mark-up showing the ability of the positive pixel algorithm to detect the staining. Digital neuropathological quantification of the IBA1 staining using the positive pixel algorithm is shown for the (b) WM, (c) sub, (d) CA1 $\left(F_{4,38}=5.0943 ; p=0.0025\right),(\mathbf{e}) C A 2 / 3\left(F_{4,38}=4.8888 ; p=0.0032\right),(\mathbf{f}) C A 4,(\mathbf{g}) D G_{1 \prime}$ and for the $(\mathbf{h})$ average of the hippocampal formation $\left(F_{4,38}=3.0201 ;\right.$ $p=0.0311$ ). Circles represent an individual case, with mean and SEM shown for the group. Statistical comparisons: ${ }^{*} p<0.05$ compared to AD cases. ${ }^{\S} p<0.05$ compared to HS-aging cases. ${ }^{\ddagger} p<0.05$ compared to AD + HS-aging cases. (i) Heatmap summarizes the results in (b-h) (also see Table 2)

and evenly distributed $250 \times 250 \mu \mathrm{m}$ regions of interest (ROI). HS-aging cases had fewer ramified microglia than $\mathrm{NC}(p=0.0091)$ or $\mathrm{AD}(p=0.0027)$ cases (Fig. 10b, Table 2). HS-aging and AD + HS-aging had the most hypertrophic microglia. AD + HS-aging cases had more hypertrophic microglia than $\mathrm{NC}(p=0.0132), \mathrm{AD}(p=0.0270)$, or DLB $(\mathrm{p}=0.0044)$ cases, and HS-aging cases had more hypertrophic microglia than DLB $(p=0.0140)$ cases (Fig. 10c, Table 2). HS-aging cases had more dystrophic microglia than $\mathrm{NC}(p=0.0005), \mathrm{AD}(p=0.0193)$, or DLB $(p=0.0225)$ cases (Fig. 10d, Table 2). Quantification of rod-shaped microglia identified a subset of cases with abundant rod-shaped microglia; however, the cases were not specific to a disease group (Fig. 10e, Table 2). $\mathrm{AD}+\mathrm{HS}$-aging cases had more amoeboid microglia than NC $(p=0.0428)$, or DLB $(p=0.0085)$ cases (Fig. 10f, Table 2). The total number of microglia in the CA1 region, regardless of morphology, was greatest in $\mathrm{HS}$-aging and $\mathrm{AD}+\mathrm{HS}$-aging. $\mathrm{AD}+\mathrm{HS}$-aging cases had more total microglia than NC $(p=0.046)$, or DLB $(p=0.0035)$ cases. HS-aging cases had more total microglia than NC $(p=0.0072)$ or DLB $(p=0.0048)$ cases (Fig. 10g, Table 2). As the total number of microglia was found to be altered in the different groups, each of the five microglia classifications was plotted as a percentage of the total number of microglia (Fig. 10h) to help visualize the microglia morphology distributions within and among the different diseases.

\section{Discussion}

The present study underscores the rich diversity of microglial morphologies in the hippocampus of the human brain that may change according to the diseases of aging. We observed regional heterogeneity in the hippocampal formation in the density and number of IBA $1^{+}$and $\mathrm{CD} 8^{+}$microglia. We also observed five morphologically-defined classes of IBA1 labeled microglia: ramified, hypertrophic, dystrophic, rod-shaped, and amoeboid (Fig. 10). Our observations provide evidence for subclasses of microglial morphologies that are seen in particular neurodegenerative diseases. The data 


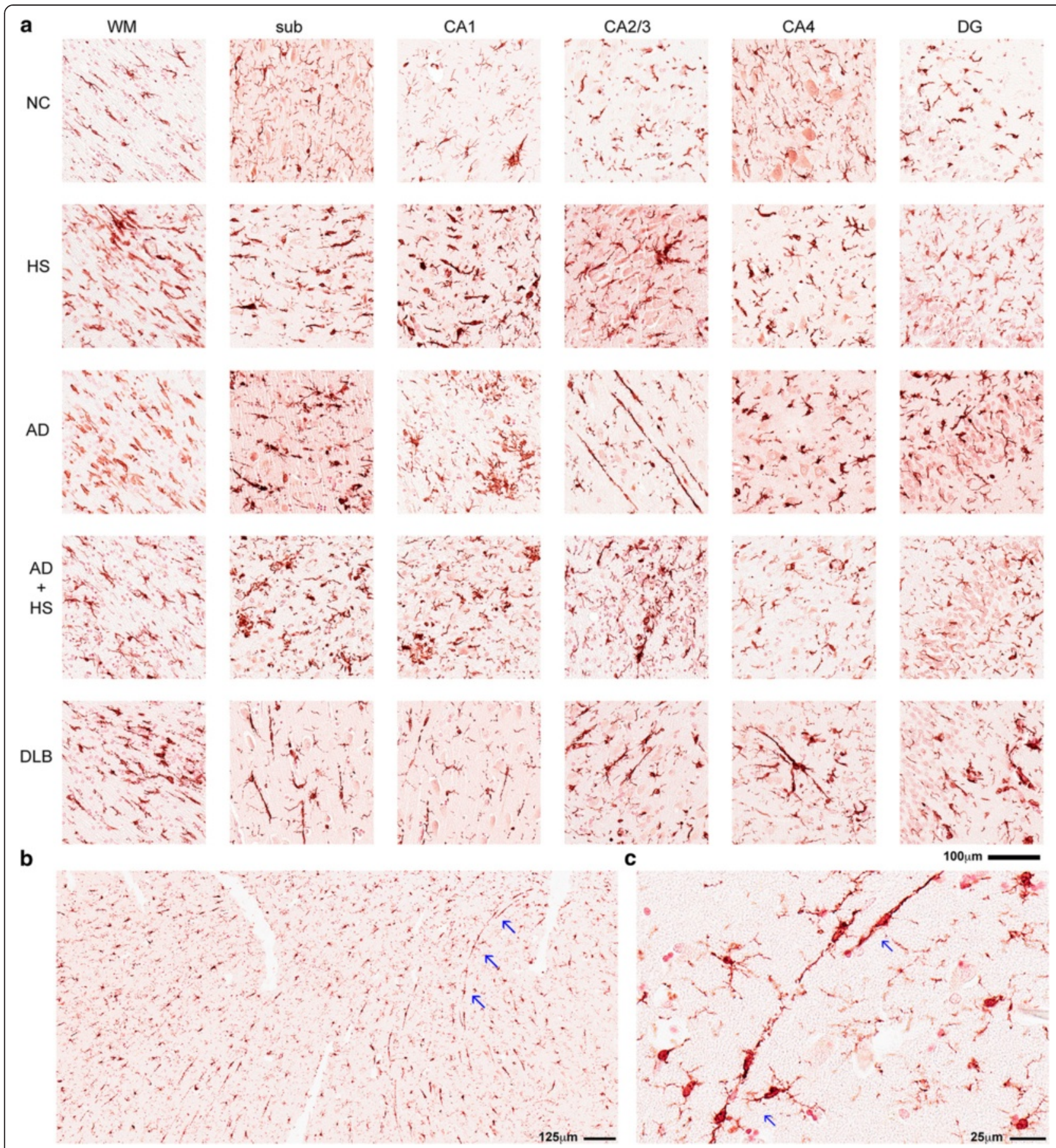

Fig. 7 Survey of $|\mathrm{BA}|^{+}$staining in the hippocampus of autopsy cases. (a) Representative examples of $\mid \mathrm{BA} 1^{+}$staining pattern in the brain regions analyzed by digital neuropathological analysis(b) A low powered photomicrograph shows the widespread distribution of rod shaped microglia in the CA1 region of a DLB individual (case \#34). Long trains of microglia (highlighted by blue arrows) are shown at higher magnification in (c).

provide at least some support for disease-specific microglia pathology in age-related dementias.

A primary goal of our project was to determine if digital neuropathological quantification could detect disease-specific changes in IBA1 and CD68 labeled microglia activation. This is the first study to use digital neuropathological quantification to measure changes in human microglia activation and compare directly the microglia response in the different neurodegenerative diseases, and the first to assess microglia in HS-aging cases. The digital neuropathological quantification was able to detect regional differences in IBA1 and CD68 

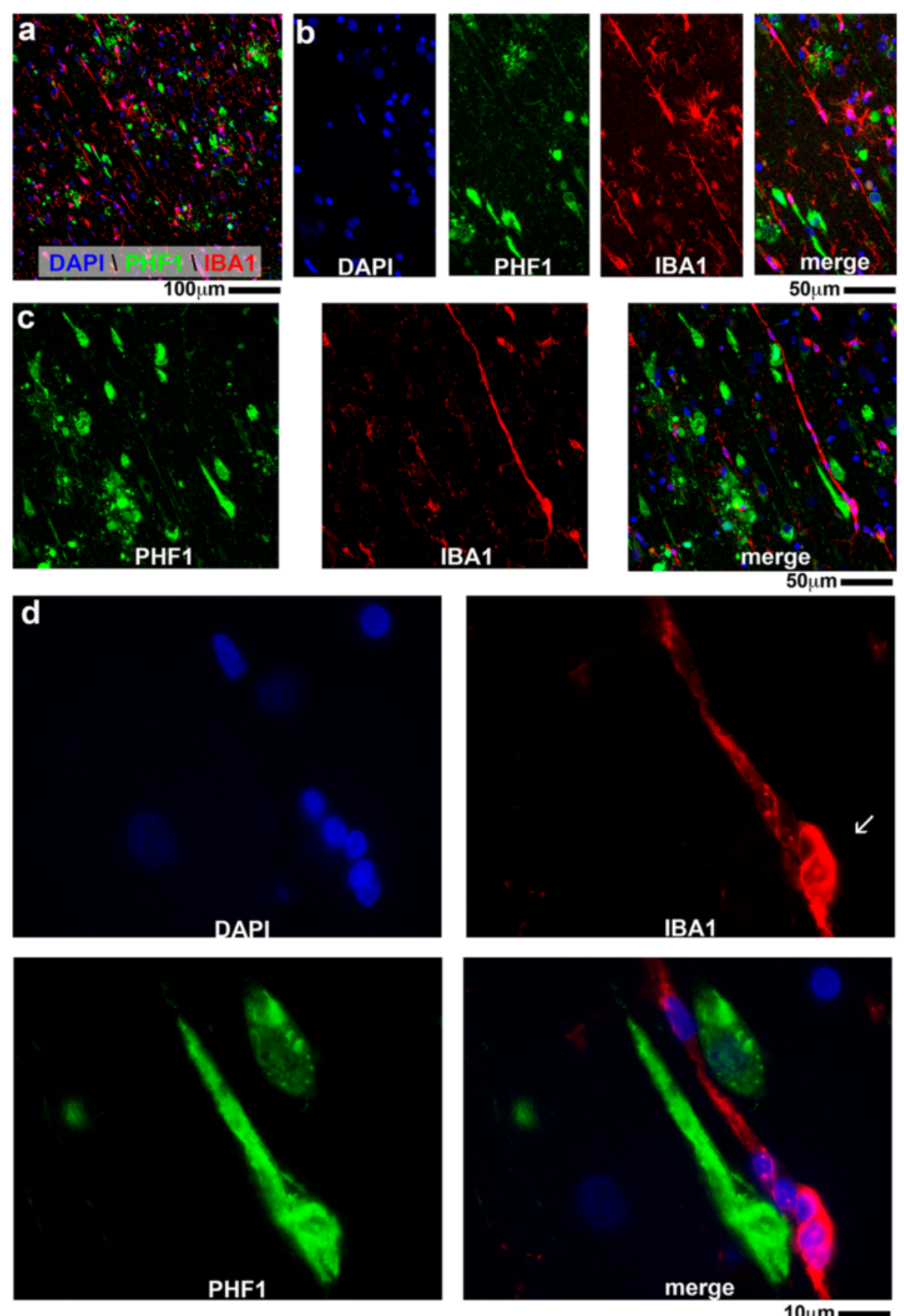

Fig. 8 Lack of localization of IBA ${ }^{+}$rod-shaped microglia to $\mathrm{PHF1}^{+}$neurons in an AD individual (case \#23). (a) A low powered photomicrograph shows the distribution of rod-shaped microglia next to $\mathrm{PHF}^{+}$cells. (b) A linear group of rod-shaped microglia is shown at a higher magnification. (c) A second example of rod-microglia, where the microglia run parallel and between PHF1+ neurons. (d) Of note, the polar end of the rod-microglia (white arrow) was found to have $5 \mathrm{DAPI}^{+}$nuclei

staining associated with the neuropathological diagnosis. Specifically, we found increased IBA1 and CD68 staining in the HS-aging and $\mathrm{AD}+\mathrm{HS}$-aging cases. Interestingly, the spatial pattern and magnitude of the changes in IBA1 and CD68 staining were remarkably similar between the $\mathrm{HS}$-aging and $\mathrm{AD}+\mathrm{HS}$-aging cases, suggesting that the HS-aging pattern of microglia staining is dominant over the $\mathrm{AD}$ pattern, and that there is not a robust additive effect of the two pathologies. Thus, results of the digital neuropathological quantification clearly show a pattern of microglia activation associated with a specific neurodegenerative 

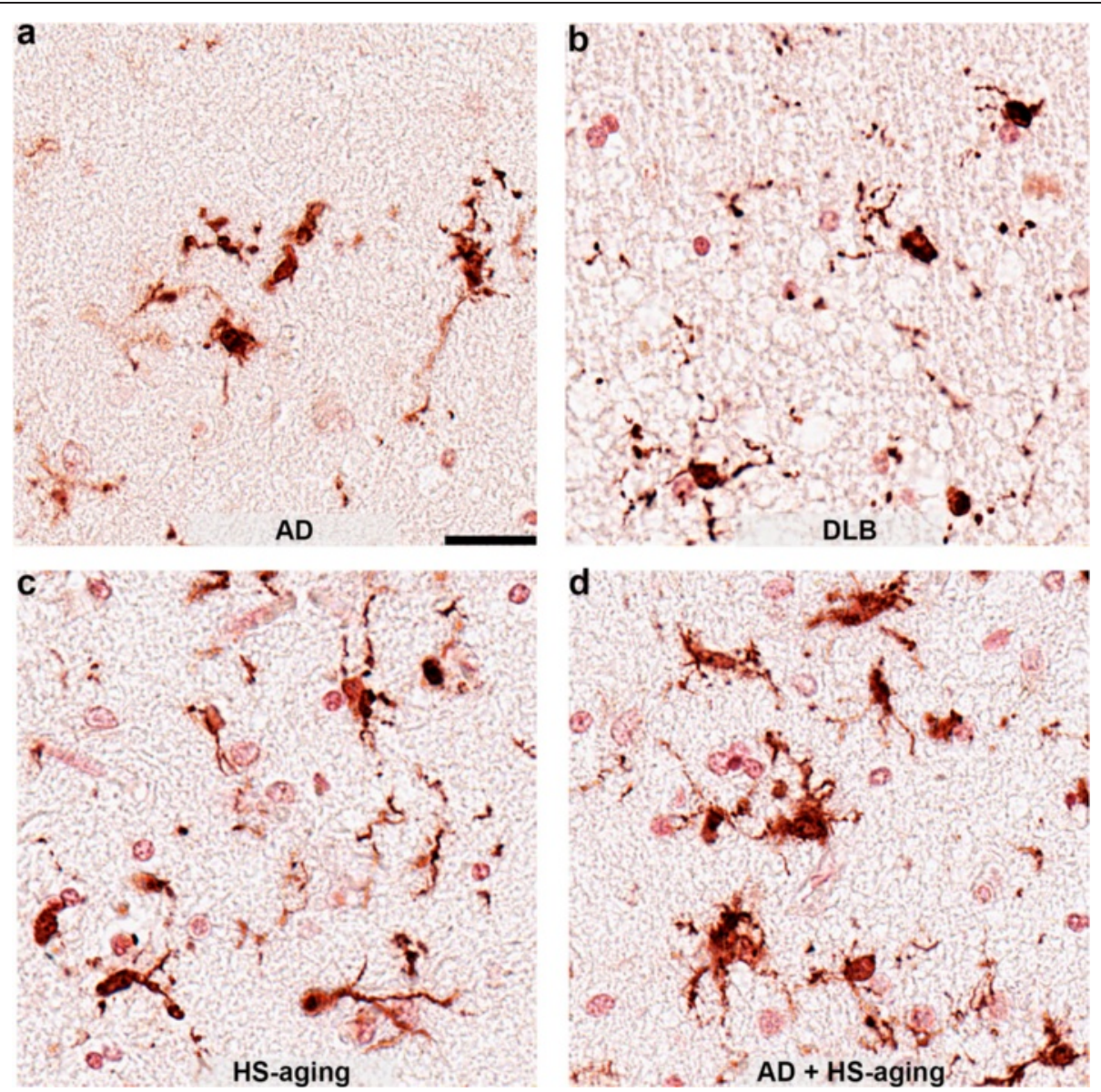

Fig. 9 Dystrophic $\mid B A 1^{+}$microglia in the hippocampus. Examples of $\mid B A 1^{+}$dystrophic microglia in the CA1 region of $A D$ individual (a; case \#20), DLB individual (b; case \#33), HS-aging individual (c; case \#15), and AD + HS-aging individual (d; case \#27). Scale bar is $25 \mu m$

disease, but overall the quantification provided only modest sensitivity, with limited diagnostic potential, to separate AD from HS-aging. To determine the reproducibility of the digital quantification, 12 of 39 cases selected at random were replicated in an independent experiment. Even with the modest sample size, a comparison of the number of IBA1 positive pixels in the CA1 regions between the two independent experiments resulted in a $R^{2}=0.7$. The results of the replication study support the use of digital neuropathological quantification as a relatively accurate, unbiased, quantitative and efficient means of neuropathological assessment. In the future, development of algorithms that can detect the different microglia phenotypes (Fig. 10) should greatly improve the potential of this approach to detect disease-related changes in microglia morphology, until specific molecular markers that recognize the different microglia morphological states are available.

The long-standing view that microglia become activated and promote neuroinflammation in neurodegenerative disease (toxic gain of function) has been challenged recently by the concept of the dystrophic / diseased microglia (loss of function; see $[25,28])$. Support for the hypofunctional (as opposed to activated) microglia model is largely based on morphological examination of IBA1-stained microglia in autopsy samples from aged humans [29-32], as currently there are no specific markers that recognize only degenerating/dystrophic microglia. In addition, the dystrophic microglia phenotype seen in humans is largely absent in rodent models [25]. This may reflect intrinsic differences in human microglia [33], or may reflect limitations in the current animal models. We found that aged individuals without dementia were more likely to have ramified microglia than individuals with dementia (AD, HS-aging, AD + HS-aging, or DLB). Moreover, the present study confirmed that dystrophic microglia are found in aged individuals and in increased numbers in aged individuals with three distinct forms of dementia (AD, HS-aging, and DLB). Our results provide an independent confirmation of the presence of dystrophic microglia described by the Streit laboratory [29-32]. Research at our center has previously shown differences in the M1/M2 microglia phenotype between mild AD and end-stage AD [34], supporting changes in the temporal dynamic of the microglia response to 


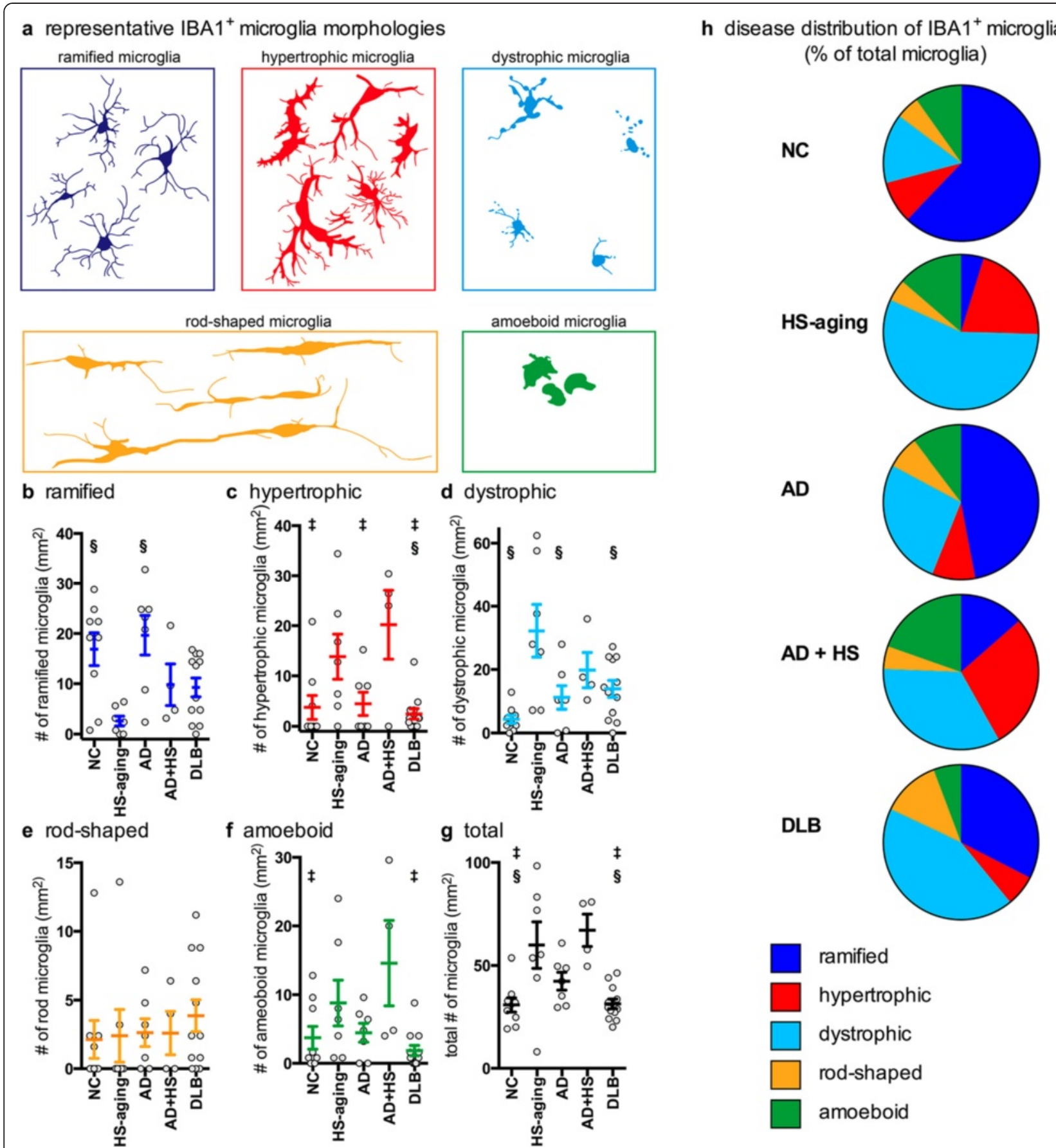

Fig. 10 Disease specific patterns in IBA $1^{+}$microglia morphology. (a) Representation of microglia morphologies seen in the hippocampus of aged individuals. The number of microglia was quantified at 40x magnification in five $250 \times 250 \mu \mathrm{m}$ regions of interest (ROIs) that were randomly placed and evenly spaced in the CA1 region. Following the classification shown in (a), IBA ${ }^{+}$microglia were classified as either $(\mathbf{b})$ ramified $\left(F_{4,38}=5.3533 ; p=0.0019\right)$, (c) hypertrophic $\left(F_{4,38}=5.5082 ; p=0.0016\right)$, (d) dystrophic $\left(F_{4,38}=5.7249 ; p=0.0012\right)$, (e) rod-shaped, or (f) amoeboid $\left(F_{4,38}=3.9836 ; p=0.0093\right)$. (g) The number of microglia $\left(F_{4,38}=7.2694 ; p=0.0002\right)$ in the five classifications was summed to get the total number of microglia. The gray circles in (b-g) represent the average number of microglia per $\mathrm{mm}^{2}$ for an individual case, with mean and SEM shown for each group (see also Table 2). Statistical comparisons: ${ }^{\$} p<0.05$ compared to HS-aging cases. ${ }^{\ddagger} p<0.05$ compared to AD + HS-aging cases. (h) As the total number of microglia significantly varied by group, the number of microglia in each of the five classifications was plotted as a percent of the total number of microglia to illustrate the disease-related patterns in microglia morphology (also see Table 2) 
varying degrees of neuropathology. Still, the temporal dynamic of microglia in humans over the course of the lifespan has not been defined and is not fully testable through autopsy (cross-sectional) studies. This is a vital area for future investigation.

The current study highlights the importance of morphology-based readout of cell activity. Rod-shaped microglia are a particularly fascinating microglia phenotype, which was first described by Nissl more than 100 years ago (reviewed in: [27]). Rod-shaped microglia have been described clinically in neurosyphilis, subacute sclerosing panencephalitis, lead encephalopathy, viral encephalitis including HIV-1, and Rasmussen's encephalitis [27, 35]; however, there are few modern reports of rod-shaped microglia in the clinical literature. In experimental models, rod-shaped microglia have been best described following traumatic brain injury [36-38, 16], where a diffuse brain injury will cause the rapid (by $6 \mathrm{~h}$ ) polarization of microglia to follow along neuronal processes. It has been shown previously in rats that microglia will fuse specifically to the apical dendrite of neurons infected with a retrovirus, but not to uninfected neurons [39]. It is not clear if fusion is occurring in the case of rod-shaped microglia in the current study. Beyond these few reported observations, little is known mechanistically about the chemoattractant signals that drive formation of rod-shaped microglia, or about the specific functions of the rod-shaped microglia in relation to the neuron. We found that rodshaped microglia could be proximal and parallel to $\mathrm{PHF}^{+}$neurons/axons, but the rod-shaped microglia did not appear to fuse with or engulf the $\mathrm{PHF}^{+}$structures. Rod-shaped microglia were present in approximately $60 \%$ of cases included in this study, but were most abundant in a subset of cases. Review of the case histories of individuals with abundant rod-shaped microglia did not identify any obvious commonalities. A goal for future studies will be to identify a larger sample of cases with abundant rod-shaped microglia to distinguish clinical-pathological correlations, as a first step in defining mechanistically the functions of this mysterious cell type.

A limitation of this study is the subjective criteria that were used to classify microglia into one of the five morphological categories (Fig. 10). This approach requires an experimenter capable of discerning differences in microglia morphology. The approach also imparts bias and potential for experimenter error. The current study demonstrates that there is a great diversity in the microglia morphology in humans, which is underappreciated, as this diversity is largely absent from animal models. There have been prior attempts to operationalize morphological changes in microglia. A recent study reconstructed microglia from mice and humans using computer-based tracing systems, and was able to provide average cell body size and roundness, along with the number of processes, process length and volume occupied by the processes [40]. That study did not include any samples without neurologic disease, and therefore underestimated the heterogeneity in microglia morphology; for example, they did not describe rod-shaped microglia. Using a similar approach, others have attempted to define classes of microglia morphology, such as the rod-shaped microglia, by calculating cell length to cell width and the number of polar vs. planar branches [36]. Moreover, others have proposed digital 3D reconstruction of the microglia as a means to quantify the microglia morphology [41]. However, before microglia morphological assessment can become standard practice in characterizing the microglia pathology, a consensus must be established on what defines different microglia morphologies, as there is currently no consensus-based agreement on definitions, or terminology for the specific classes of microglia morphology. Our study provides a first step towards this goal and will hopefully provide a framework to move the field forward in this direction.

\section{Conflict of interests}

The authors declare that they have no competing interests

\section{Acknowledgements}

We are profoundly grateful to all of the study participants who make this research possible. The corresponding author, Adam Bachstetter, PhD, had full access to all of the data in the study and takes responsibility for the integrity of the data and the accuracy of the data analysis. Research reported in this publication was supported by National Institutes of Health under award numbers P30 AG028383, K99 AG044445. The content is solely the responsibility of the authors and does not represent the official views of the National Institutes of Health.

\section{Author details}

${ }^{1}$ Sanders-Brown Center on Aging, University of Kentucky, 800 S. Limestone St, Lexington, KY, USA. ${ }^{2}$ Department of Anatomy and Neurobiology, University of Kentucky, Lexington, KY, USA. ${ }^{3}$ Department of Neurology, University of Kentucky, Lexington, KY, USA. ${ }^{4}$ Department of Pathology and Laboratory Medicine, Division of Neuropathology, University of Kentucky, Lexington, KY, USA. ${ }^{5}$ Department of Epidemiology, University of Kentucky, Lexington, KY, USA. ' Department of Biostatistics, University of Kentucky, Lexington, KY, USA. ${ }^{7}$ Department of Statistics, University of Kentucky, Lexington, KY, USA.

Received: 1 May 2015 Accepted: 4 May 2015

Published online: 23 May 2015

\section{References}

1. Malik M, Simpson JF, Parikh I, Wilfred BR, Fardo DW, Nelson PT, Estus S (2013) CD33 Alzheimer's risk-altering polymorphism, CD33 expression, and exon 2 splicing. J Neurosci 33(33):13320-13325. doi:10.1523/JNEUROSCI.1224-13.2013

2. Griciuc A, Serrano-Pozo A, Parrado AR, Lesinski AN, Asselin CN, Mullin K, Hooli B, Choi SH, Hyman BT, Tanzi RE (2013) Alzheimer's disease risk gene CD33 inhibits microglial uptake of amyloid beta. Neuron 78(4):631-643. doi:10.1016/j.neuron.2013.04.014

3. Jonsson T, Stefansson H, Steinberg S, Jonsdottir I, Jonsson PV, Snaedal J, Bjornsson S, Huttenlocher J, Levey Al, Lah JJ, Rujescu D, Hampel H, Giegling I, Andreassen OA, Engedal K, Ulstein I, Djurovic S, Ibrahim-Verbaas C, Hofman A, Ikram MA, van Duijn CM, Thorsteinsdottir U, Kong A, Stefansson K (2013) Variant of TREM2 associated with the risk of Alzheimer's disease. N Engl J Med 368(2):107-116. doi:10.1056/NEJMoa1211103

4. Guerreiro R, Wojtas A, Bras J, Carrasquillo M, Rogaeva E, Majounie E, Cruchaga C, Sassi C, Kauwe JS, Younkin S, Hazrati L, Collinge J, Pocock J, 
Lashley T, Williams J, Lambert JC, Amouyel P, Goate A, Rademakers R, Morgan K, Powell J, St George-Hyslop P, Singleton A, Hardy J, Alzheimer Genetic Analysis G (2013) TREM2 variants in Alzheimer's disease. N Engl J Med 368(2):117-127. doi:10.1056/NEJMoa1211851

5. Kettenmann H, Hanisch UK, Noda M, Verkhratsky A (2011) Physiology of microglia. Physiol Rev 91(2):461-553. doi:10.1152/physrev.00011.2010

6. Butovsky O, Jedrychowski MP, Moore CS, Cialic R, Lanser AJ, Gabriely G, Koeglsperger T, Dake B, Wu PM, Doykan CE, Fanek Z, Liu L, Chen Z, Rothstein JD, Ransohoff RM, Gygi SP, Antel JP, Weiner HL (2014) Identification of a unique TGF-beta-dependent molecular and functional signature in microglia. Nat Neurosci 17(1):131-143. doi:10.1038/nn.3599

7. Hickman SE, Kingery ND, Ohsumi TK, Borowsky ML, Wang LC, Means TK, El Khoury J (2013) The microglial sensome revealed by direct RNA sequencing. Nat Neurosci 16(12):1896-1905. doi:10.1038/nn.3554

8. Davalos D, Grutzendler J, Yang G, Kim JV, Zuo Y, Jung S, Littman DR, Dustin ML, Gan WB (2005) ATP mediates rapid microglial response to local brain injury in vivo. Nat Neurosci 8(6):752-758. doi:10.1038/nn1472

9. Nimmerjahn A, Kirchhoff F, Helmchen F (2005) Resting microglial cells are highly dynamic surveillants of brain parenchyma in vivo. Science 308(5726):1314-1318. doi:10.1126/science.1110647

10. Nelson PT, Alafuzoff I, Bigio EH, Bouras C, Braak H, Cairns NJ, Castellani RJ, Crain BJ, Davies P, Del Tredici K, Duyckaerts C, Frosch MP, Haroutunian V, Hof PR, Hulette CM, Hyman BT, Iwatsubo T, Jellinger KA, Jicha GA, Kovari E, Kukull WA, Leverenz JB, Love S, Mackenzie IR, Mann DM, Masliah E, McKee AC, Montine TJ, Morris JC, Schneider JA, Sonnen JA, Thal DR, Trojanowski JQ, Troncoso JC, Wisniewski T, Woltjer RL, Beach TG (2012) Correlation of Alzheimer disease neuropathologic changes with cognitive status: a review of the literature. $J$ Neuropathol Exp Neurol 71(5):362-381. doi:10.1097/NEN.0b013e31825018f7

11. Nelson PT, Smith CD, Abner EL, Wilfred BJ, Wang WX, Neltner JH, Baker M, Fardo DW, Kryscio RJ, Scheff SW, Jicha GA, Jellinger KA, Van Eldik LJ, Schmitt FA (2013) Hippocampal sclerosis of aging, a prevalent and high-morbidity brain disease. Acta Neuropathol 126(2):161-177. doi:10.1007/s00401-013-1154-1

12. Kurushima H, Ramprasad M, Kondratenko N, Foster DM, Quehenberger O, Steinberg D (2000) Surface expression and rapid internalization of macrosialin (mouse CD68) on elicited mouse peritoneal macrophages. J Leukoc Biol 67(1):104-108

13. da Silva RP, Gordon S (1999) Phagocytosis stimulates alternative glycosylation of macrosialin (mouse CD68), a macrophage-specific endosomal protein. Biochem J 338(Pt 3):687-694

14. Ito D, Imai Y, Ohsawa K, Nakajima K, Fukuuchi Y, Kohsaka S (1998) Microglia-specific localisation of a novel calcium binding protein, Iba1. Brain Res Mol Brain Res 57(1):1-9

15. Schmitt FA, Nelson PT, Abner E, Scheff S, Jicha GA, Smith C, Cooper G, Mendiondo M, Danner DD, Van Eldik L, Caban-Holt A, Lovell MA, Kryscio RJ (2012) University of Kentucky Sanders-Brown healthy brain aging volunteers: donor characteristics, procedures and neuropathology. Curr Alzheimer Res 9(6):724-733

16. Bachstetter AD, Rowe RK, Kaneko M, Goulding D, Lifshitz J, Van Eldik L (2013) The p38alpha MAPK regulates microglial responsiveness to diffuse traumatic brain injury. J Neurosci 33(14):6143-6153. doi:10.1523/ JNEUROSCI.5399-12.2013

17. Bachstetter AD, Norris CM, Sompol P, Wilcock DM, Goulding D, Neltner JH, St Clair D, Watterson DM, Van Eldik LJ (2012) Early stage drug treatment that normalizes proinflammatory cytokine production attenuates synaptic dysfunction in a mouse model that exhibits age-dependent progression of Alzheimer's disease-related pathology. J Neurosci 32(30):10201-10210. doi:10.1523/JNEUROSCl.1496-12.2012

18. Schmider E, Ziegler M, Danay E, Beyer L, Bühner M (2010) Is It Really Robust? Methodology: European Journal of Research Methods for the Behavioral and Social Sciences 6(4):147-151. doi:10.1027/1614-2241/a000016

19. Leverenz JB, Agustin CM, Tsuang D, Peskind ER, Edland SD, Nochlin D, DiGiacomo L, Bowen JD, McCormick WC, Teri L, Raskind MA, Kukull WA, Larson EB (2002) Clinical and neuropathological characteristics of hippocampal sclerosis - A community-based study. Arch Neurol 59(7):1099-1106. doi:10.1001/archneur.59.7.1099

20. Nelson PT, Schmitt FA, Lin YS, Abner EL, Jicha GA, Patel E, Thomason PC, Neltner JH, Smith CD, Santacruz KS, Sonnen JA, Poon LW, Gearing M, Green RC, Woodard JL, Van Eldik LJ, Kryscio RJ (2011) Hippocampal sclerosis in advanced age: clinical and pathological features. Brain 134:1506-1518. doi:10.1093/brain/awr053
21. Dickson DW, Davies P, Bevona C, Vanhoeven KH, Factor SM, Grober E, Aronson MK, Crystal HA (1994) Hippocampal sclerosis - a common pathological feature of dementia in very old (greater-than-or-equal-to-80 years of age) humans. Acta Neuropathol 88(3):212-221

22. West MJ (1993) New stereological methods for counting neurons. Neurobiol Aging 14(4):275-285

23. Sterio DC (1984) The unbiased estimation of number and sizes of arbitrary particles using the disector. J Microsc 134(Pt 2):127-136

24. Streit WJ (2006) Microglial senescence: does the brain's immune system have an expiration date? Trends Neurosci 29(9):506-510. doi:10.1016/ j.tins.2006.07.001

25. Streit WJ, Xue QS, Tischer J, Bechmann I (2014) Microglial pathology. Acta Neuropathol Commun 2(1):142. doi:10.1186/s40478-014-0142-6

26. Boche D, Perry VH, Nicoll JA (2013) Review: activation patterns of microglia and their identification in the human brain. Neuropathol Appl Neurobiol 39(1):3-18. doi:10.1111/nan.12011

27. Graeber MB (2010) Changing face of microglia. Science 330(6005):783-788. doi:10.1126/science.1190929

28. Mosher Kl, Wyss-Coray T (2014) Microglial dysfunction in brain aging and Alzheimer's disease. Biochem Pharmacol 88(4):594-604. doi:10.1016/ j.bcp.2014.01.008

29. Streit WJ, Braak H, Xue QS, Bechmann I (2009) Dystrophic (senescent) rather than activated microglial cells are associated with tau pathology and likely precede neurodegeneration in Alzheimer's disease. Acta Neuropathol 118(4):475-485. doi:10.1007/s00401-009-0556-6

30. Xue QS, Streit WJ (2011) Microglial pathology in down syndrome. Acta Neuropathol 122(4):455-466. doi:10.1007/s00401-011-0864-5

31. Lopes KO, Sparks DL, Streit WJ (2008) Microglial dystrophy in the aged and Alzheimer's disease brain is associated with ferritin immunoreactivity. Glia 56(10):1048-1060. doi:10.1002/glia.20678

32. Streit WJ, Sammons NW, Kuhns AJ, Sparks DL (2004) Dystrophic microglia in the aging human brain. Glia 45(2):208-212. doi:10.1002/glia.10319

33. Smith AM, Dragunow M (2014) The human side of microglia. Trends Neurosci 37(3):125-135. doi:10.1016/j.tins.2013.12.001

34. Sudduth TL, Schmitt FA, Nelson PT, Wilcock DM (2013) Neuroinflammatory phenotype in early Alzheimer's disease. Neurobiol Aging 34(4):1051-1059. doi:10.1016/jneurobiolaging.2012.09.012

35. Wirenfeldt M, Clare R, Tung S, Bottini A, Mathern GW, Vinters HV (2009) Increased activation of Iba1(+) microglia in pediatric epilepsy patients with Rasmussen's encephalitis compared with cortical dysplasia and tuberous sclerosis complex. Neurobiol Dis 34(3):432-440. doi:10.1016/ j.nbd.2009.02.015

36. Taylor SE, Morganti-Kossmann C, Lifshitz J, Ziebell JM (2014) Rod microglia: a morphological definition. PLoS One 9(5), e97096. doi:10.1371/ journal.pone.0097096

37. Ziebell JM, Taylor SE, Cao TX, Harrison JL, Lifshitz J (2012) Rod microglia: elongation, alignment, and coupling to form trains across the somatosensory cortex after experimental diffuse brain injury. Neuroinflammation 9. doi:10.1186/1742-2094-9-247

38. Cao T, Thomas TC, Ziebell JM, Pauly JR, Lifshitz J (2012) Morphological and genetic activation of microglia after diffuse traumatic brain injury in the rat. Neuroscience 225:65-75. doi:10.1016/..neuroscience.2012.08.058

39. Ackman JB, Siddiqi F, Walikonis RS, LoTurco JJ (2006) Fusion of microglia with pyramidal neurons after retroviral infection. J Neurosci 26(44):11413-11422. doi:10.1523/JNEUROSCI.3340-06.2006

40. Torres-Platas SG, Comeau S, Rachalski A, Dal Bo G, Cruceanu C, Turecki G, Giros B, Mechawar N (2014) Morphometric characterization of microglial phenotypes in human cerebral cortex. J Neuroinflammation 11. doi:10.1186/ 1742-2094-11-12

41. Beynon SB, Walker FR (2012) Microglial activation in the injured and healthy brain: What are we really tallkine about? Practical and theoretical issues associated with measurement of changes in microglia morphology. Neuroscience 225:162-171. doi:10.1016/j.neuroscience.2012.07.029

42. Nelson PT, Abner EL, Schmitt FA, Kryscio RJ, Jicha GA, Smith CD, Davis DG, Poduska JW, Patel E, Mendiondo MS, Markesbery WR (2010) Modeling the association between 43 different clinical and pathological variables and the severity of cognitive impairment in a large autopsy cohort of elderly persons. Brain Pathol 20(1):66-79. doi:10.1111/j.1750-3639.2008.00244.x 